\title{
Collapse of polar ice sheets during the stage 11 interglacial
}

\author{
Maureen E. Raymo ${ }^{1}$ \& Jerry X. Mitrovica ${ }^{2}$
}

Contentious observations of Pleistocene shoreline features on the tectonically stable islands of Bermuda and the Bahamas have suggested that sea level about 400,000 years ago was more than 20 metres higher than it is today ${ }^{1-4}$. Geochronologic and geomorphic evidence indicates that these features formed during interglacial marine isotope stage (MIS) 11, an unusually long interval of warmth during the ice age $\mathrm{a}^{1-4}$. Previous work has advanced two divergent hypotheses for these shoreline features: first, significant melting of the East Antarctic Ice Sheet, in addition to the collapse of the West Antarctic Ice Sheet and the Greenland Ice Sheet ${ }^{1-3}$; or second, emplacement by a mega-tsunami during MIS 11 (ref. 4, 5). Here we show that the elevations of these features are corrected downwards by $\sim 10$ metres when we account for post-glacial crustal subsidence of these sites over the course of the anomalously long interglacial. On the basis of this correction, we estimate that eustatic sea level rose to $\sim 6-13 \mathrm{~m}$ above the present-day value in the second half of MIS 11 . This suggests that both the Greenland Ice Sheet and the West Antarctic Ice Sheet collapsed during the protracted warm period while changes in the volume of the East Antarctic Ice Sheet were relatively minor, thereby resolving the long-standing controversy over the stability of the East Antarctic Ice Sheet during MIS 11.

The stability of ice sheets in the face of continuing global warming is an issue of significant societal concern. Satellite gravity measurements indicate that the Greenland Ice Sheet (GIS) and the West Antarctic Ice Sheet (WAIS), the two ice sheets most susceptible to climate change, are experiencing a net mass loss ${ }^{6-9}$, with evidence of an accelerating pace $^{9-12}$. In contrast, the current mass balance of the much larger East Antarctic Ice Sheet (EAIS) is uncertain, even in sign ${ }^{6,9}$, though a recent study ${ }^{11}$ has inferred EAIS mass loss localized to coastal regions. This uncertainty about the stability of the EAIS in a progressively warming world has been a key motivation for studies of the palaeoclimate record during past warm intervals.

One such study, a statistical analysis of widely distributed sea-level markers related to the last interglacial (MIS 5e; about 120,000 years ago), concluded with $95 \%$ confidence that eustatic sea level (ESL; defined as the globally averaged sea-level change) was $>6.6 \mathrm{~m}$ higher during MIS $5 \mathrm{e}$ than at the present day, and with $66 \%$ confidence that ESL was $>8.0 \mathrm{~m} \mathrm{higher}^{13}$. (This inference, higher than earlier estimates ${ }^{14}$, is supported by a recent analysis of MIS $5 \mathrm{e}$ sea-level records from Florida $^{15}$.) Estimates of the ESL rise associated with collapse of polar ice sheets range from $3.4 \mathrm{~m}$ (ref. 16) to $7 \mathrm{~m}$ for the GIS, and from $3.2 \mathrm{~m}$ (ref. 17) to $5 \mathrm{~m}$ for the WAIS, where the upper bounds refer to the complete disappearance of the ice sheet. Thus, whereas the estimate of peak ESL during MIS 5e implies significant collapse of both the GIS and the WAIS, it also implies that the EAIS remained relatively stable.

It is within this context of assessing potential future instability of the EAIS that the sea-level highstand features found at $\sim 20 \mathrm{~m}$ (here and elsewhere, height above present-day sea level is meant) in Bermuda and the Bahamas, and which formed during the MIS 11 interglacial ( 424-395 kyr ago), have taken on great significance. MIS 11 spanned two precession cycles and was the longest interglacial of the past
500 kyr (refs 18, 19), including the current interglacial MIS 1 (Fig. 1) and MIS 5e (Supplementary Fig. 4). If the ESL during the MIS 11 interglacial peaked at a level $20 \mathrm{~m}$ higher than today $^{1-3}$, then at least $8 \mathrm{~m}$ of that rise must have come from melting of the EAIS. Geologic evidence for a $\sim 20$-m sea-level highstand in Bermuda and the Bahamas is convincing. In Bermuda, reasonably well-dated deposits with thalassinidean shrimp burrows, foraminifera, and gastropods characteristic of littoral and intertidal environments constrain relative sea level at $21.3 \pm 1.0 \mathrm{~m}$ during MIS 11 (refs. 2, 3). On Eleuthera, in the Bahamas, a gently sloping erosion surface capped with fenestrae-rich intertidal beach deposits provides a maximum sea-level estimate of $20 \pm 3 \mathrm{~m}$, and the occurrence of pendant fibrous cements suggests a minimum sea level of $17 \pm 2 \mathrm{~m}$ (we will henceforth quote a sea-level estimate of $18.5 \pm 3.6 \mathrm{~m}$ for this site); multiple dating methods suggest that these deposits were formed during MIS 11 (ref. 1).

How do these observations compare to other MIS 11 sea-level indicators or proxies? In a recent survey of MIS 11 sea-level records worldwide (most of which are located in tectonically active regions), Bowen $^{5}$ estimated peak MIS 11 sea level using a range of tectonic uplift

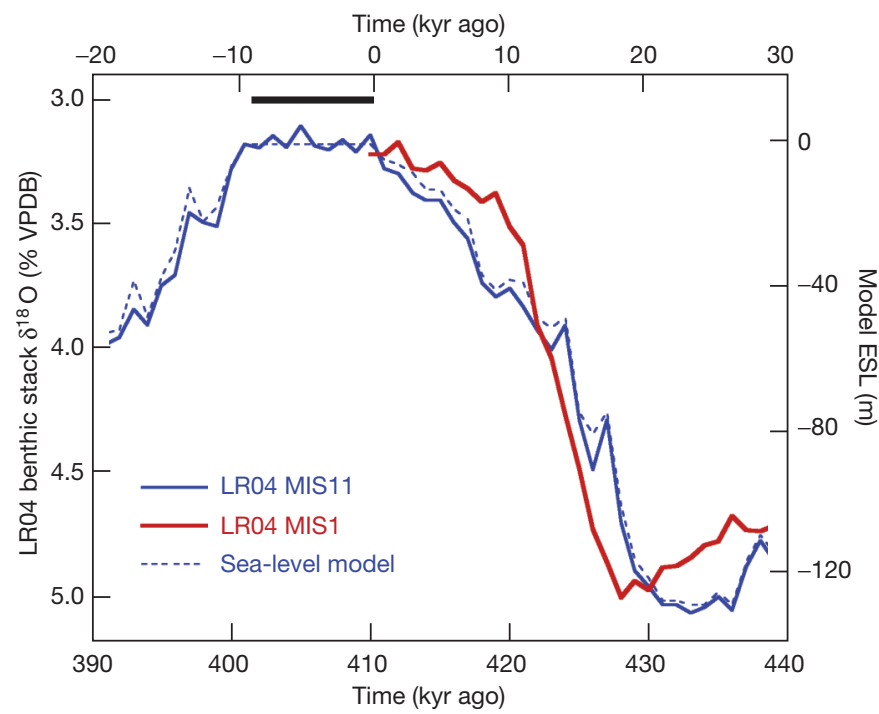

Figure 1 Comparison of the duration of the MIS 11 and MIS 1 interglacials. Plot of the LR04 benthic oxygen isotope stack ${ }^{28}$ (left-hand vertical axis) over a time window spanning the MIS 11 (blue; bottom time scale) and MIS 1 (red; top time scale) interglacials. The mean standard error on $\delta^{18} \mathrm{O}$ in the LR0 4 stack is $0.06 \%$ with an age error of $\pm 4 \mathrm{kyr}$ for the intervals considered here. The juxtaposition illustrates the significantly longer duration of maximum interglacial conditions during MIS 11 relative to MIS 1. ESL associated with the model ice history used to calculate GIA effects during MIS 11 is shown by dashed line (right-hand vertical axis). Note the hiatus in model ice volume changes from 410 to $401 \mathrm{kyr}$ ago (black bar). An analogous comparison between the duration of MIS 11 with MIS $5 \mathrm{e}$ can be found in Supplementary Fig. 4. 
corrections based on different assumed ages and elevations of MIS 5e sea-level markers. If we adopt Kopp et al.'s ${ }^{13}$ recent inference of the age and peak magnitude of ESL during MIS $5 \mathrm{e}$ as a constraint on the latter, then Bowen's estimates from far-field sites imply that peak sea level during MIS 11 was $6-9 \mathrm{~m}$ above the present-day value, an estimate consistent with marine $\delta^{18} \mathrm{O}$ isotopic anomalies ${ }^{20}$. However, Bowen excluded a number of outliers, including the well-studied Bermuda and Bahamas sites, and following McMurtry et al. ${ }^{4}$, he attributed the anomalously high elevation of shoreline features at those sites to deposition by storms or a mega-tsunami.

The two explanations for the MIS 11 highstand features in Bermuda and the Bahamas-global sea-level rise associated with significant EAIS melting $^{1-3}$, or mega-tsunami deposition ${ }^{4,5}$-ignore the potential signal from glacial isostatic adjustment (GIA). The GIA signal may be significant at the two sites, as they both are located on the peripheral bulge of the ancient Laurentian ice complex. As a consequence, they would be subject to local crustal subsidence and sea-level rise of amplitude $\sim 1-2 \mathrm{~mm} \mathrm{yr}^{-1}$ during any interglacial ${ }^{21}$.

To explore the potential contribution from GIA to MIS 11 highstand elevations, we compute global sea-level variations over the past $500 \mathrm{kyr}$ using a gravitationally self-consistent theory valid for spherically symmetric, linear viscoelastic Earth models ${ }^{22}$ (see Supplementary Information). As an illustration of the physics of interglacial sea-level trends, we plot the predicted change in sea level across the warmest, most stable interval in MIS 11 (as implied by $\delta^{18} \mathrm{O}$ records), a 9-kyr period spanning 410-401 kyr ago that occurred during the second half of MIS 11 (Fig. 2). The predictions adopt an Earth model with uppermantle and lower-mantle viscosities of $5 \times 10^{20} \mathrm{~Pa} \mathrm{~s}$ and $5 \times 10^{21} \mathrm{~Pa} \mathrm{~s}$, respectively (model $\mathrm{LM}^{23,24}$; see Supplementary Information).

In the near-field of the former MIS 12 ice sheets, the predicted sealevel change is dominated by radial crustal motions. For example, in regions once covered by ice sheets, post-glacial rebound of the crust produces a sea-level fall of amplitude up to $\sim 1-2 \mathrm{~cm} \mathrm{yr}^{-1}$, leading to a net fall over $9 \mathrm{kyr}$ that can exceed $100 \mathrm{~m}$ (these amplitudes are well off the scale of Fig. 2). Surrounding these regions of uplift are peripheral bulges predicted to subside at rates of up to $0.2-0.3 \mathrm{~cm} \mathrm{yr}^{-1}$ during the interglacial. This subsidence accounts for the (red) zones of sea-level rise in Fig. 2, with maximum amplitude of $\sim 20 \mathrm{~m}$, that encircle the Laurentian, Fennoscandian and Antarctic ice complexes. In contrast, a sea-level fall of $2-3 \mathrm{~m}$ is predicted across most of the far-field of the former ice sheets during MIS 11. This fall is due to a combination of two processes: (1) deglaciation-induced ocean loading effects, which act, near continental margins, to tilt the crust such that continents are deformed upward (that is, sea level falls) and offshore regions downward ${ }^{21,25}$; and (2) the redistribution-or syphoning-of water from ocean basins towards regions of peripheral bulge and offshore subsidence $^{21}$.

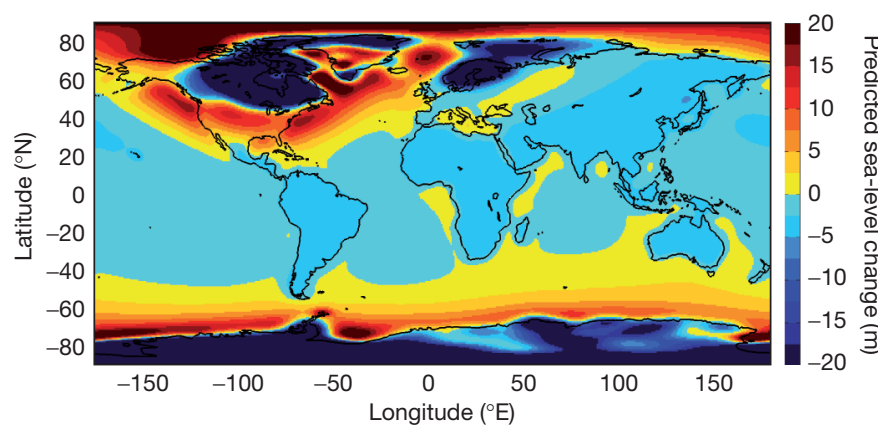

Figure $2 \mid$ Predicted sea-level change across the hiatus in ice volume changes (410-401 kyr ago) spanned by the model MIS 11 interglacial. The GIA calculation is based on the ice history discussed in Supplementary Information and the $\mathrm{LM}^{23,24}$ viscosity model. The colour scale saturates in regions within the near-field of the late Pleistocene ice sheets.
Following Fig. 2, we conclude that in the absence of interglacial ice volume changes and steric effects, sea-level highstands will date to the end of the interglacial at sites within the subsiding peripheral bulge of major ice centres, and to the beginning of the interglacial over most of the far-field (Fig. 3). (Of course, any sea-level signal associated with interglacial ice volume variations and with ocean temperature and salinity changes will be superimposed on these predicted GIA trends.) Consider Bermuda: the predicted relative sea-level history for this site (Fig. 3 and Supplementary Fig. 1, solid red line) exhibits a monotonic rise across MIS 11, reaching a level $11.9 \mathrm{~m}$ above the present-day value. The predicted highstand for the Bahamas (dashed red line, Fig. 3), lying on the outer flank of the same peripheral bulge, is $7.4 \mathrm{~m}$. It is clear that the amplitude of highstands at Bermuda or the Bahamas, indeed at all sites within a peripheral bulge, will be a strong function of the duration of the interglacial highstand. In this regard, the protracted length of MIS 11, relative to the Holocene (Fig. 1) or MIS 5e (Supplementary Fig. 4), should be manifested by highstands of particularly large magnitude. From this it also follows that simple field comparisons of the relative elevations of Holocene, MIS 5e and MIS 11 sea-level markers on these islands would lead to an erroneous assessment of the difference in ESL between those times.

This result may be stated with more generality. The elevation of an ancient interglacial highstand at any site within a peripheral bulge will be governed by the difference in the state of isostatic disequilibrium at the end of the ancient interglacial relative to the disequilibrium at the present day in that same location. As the MIS 11 interglacial was significantly longer than the current interglacial (or MIS 5e), more subsidence had occurred by the time the final MIS 11 shoreline indicators were emplaced on those islands than during the current (or MIS 5e) interglacial. Further, as the current interglacial proceeds, sites like Bermuda and the Bahamas will be subject to a continuing sea-level rise as the present peripheral bulge continues to subside. Thus, the height of these ancient MIS 11 highstand features will progressively fall as time progresses (even in the absence of any future change in ice volume).

By contrast, the highstand amplitude at sites located in the far field will depend on the difference in isostatic disequilibrium at the beginning of the interglacial relative to the disequilibrium at the present day.

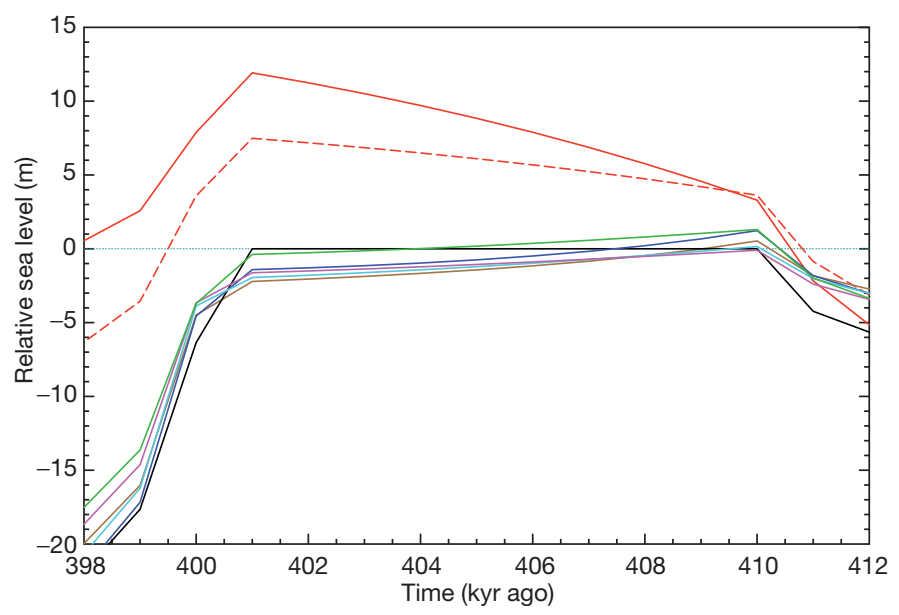

Figure $3 \mid$ Predicted relative sea-level changes across the model MIS 11 interglacial. The calculations are based on the ice history discussed in Supplementary Information and the LM viscosity model. The top two curves are predictions for Bermuda (solid red line) and the Bahamas (dashed red line) at locations of published data discussed in text. The lower coloured curves, predictions for a number of far-field sites, are included for comparison: the Gulf of Aden, Red Sea (brown), Curacao (green), Coorong, South Australia (magenta), Oahu, Hawaii (blue) and Cape Town, South Africa (cyan). The black line shows the ESL variation associated with the adopted ice history (as in the dashed blue line in Fig. 1 and the black line in Supplementary Fig. 1) and the thin horizontal dashed line references to present-day sea level. 
Thus, perhaps counter-intuitively, the current elevation of these highstands does not depend on the duration of the ancient interglacial.

Global predictions of current MIS 11 shoreline elevations within each of the two zones discussed above are shown in Fig. 4a and b: Fig. 4a encompasses sites where the highstand occurred at the end of the modelled interglacial hiatus in ice mass change (for example, $401 \mathrm{kyr}$ ago) whereas Fig. $4 \mathrm{~b}$ encompasses sites where the highstand occurs at the beginning of the modelled hiatus $(410 \mathrm{kyr}$ ago). These results represent the predicted contribution to observed MIS 11 highstands from GIA alone; this contaminating signal should be removed from geological observations before they are used to infer the difference in ESL (or ice volume) between MIS 11 and the present.

As noted above, the GIA contribution to the MIS 11 shoreline elevations in Bermuda and the Bahamas is predicted to be $11.9 \mathrm{~m}$ and $7.4 \mathrm{~m}$, respectively (Fig. 3). Correcting the published highstand estimates at these sites for these GIA predictions yields residual MIS 11 sea-level elevations of $9.4 \pm 1 \mathrm{~m}$ for Bermuda and $11.1 \pm 3.6 \mathrm{~m}$ in Eleuthera (Supplementary Table 1). Although additional field observations in the Bahamas could greatly decrease the multi-metre error associated with these sea-level estimates, we conclude that no significant contribution from melting of the EAIS is required to explain the geologic observations at the two sites.

In our analysis, we implicitly assume that melting of the WAIS and the GIS occurred towards the end of the MIS 11 interglacial, such that the contribution of the melt event to sea level at Bermuda and the Bahamas could be added to a coeval GIA-induced highstand. This timing for ice sheet collapse is strongly supported by at least two arguments. First, if the collapse took place at the beginning of the hiatus in MIS 11 melting (that is, at $\sim 410 \mathrm{kyr}$ ago), then the associated ESL rise would have had to be close to $20 \mathrm{~m}$ in order to fit the observed highstand elevations at Bermuda and the Bahamas. However, in this case, the predicted highstand elevation at far-field sites would have been even greater than $20 \mathrm{~m}$ (that is, an $\sim 20-\mathrm{m}$ melt signal added to the GIA-induced highstand of a few metres; Fig. 3), a situation apparently ruled out by far-field observations ${ }^{5}$. Second, GIA calculations predict a submergence of up to several metres for far-field sites by $401 \mathrm{kyr}$ ago (Fig. 3) and an average submergence of $\sim 1 \mathrm{~m}$ at the specific far-field
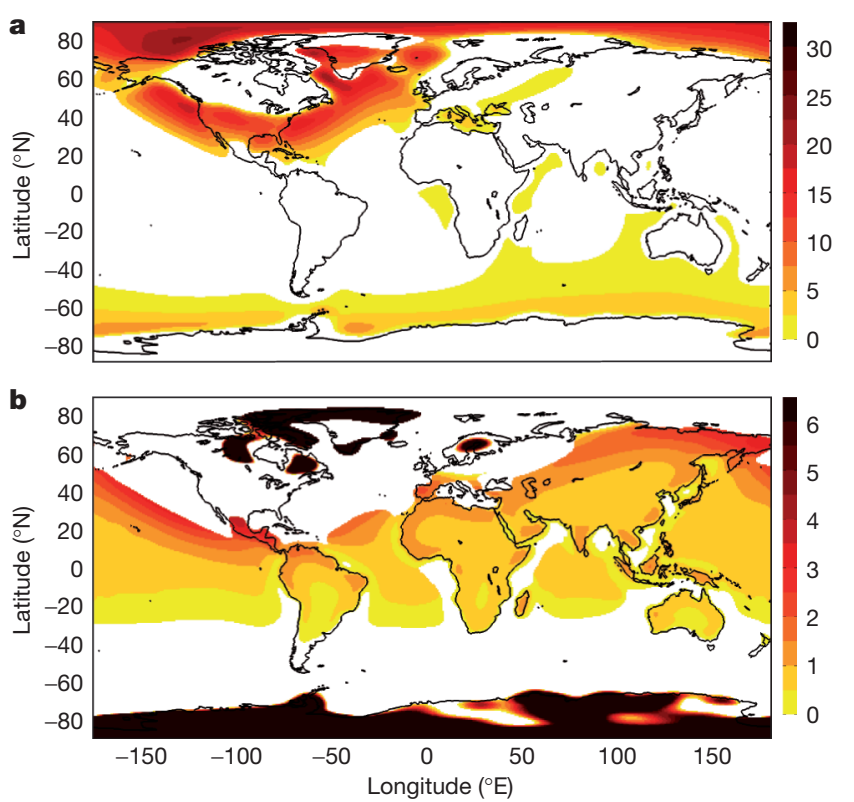

Figure $4 \mid$ Plot of the predicted GIA-induced present-day elevation of MIS 11 highstands that are currently greater than zero. Elevation is shown for all sites in which sea-level peaks either at the end of the hiatus in ice volume changes spanned by the model MIS 11 interglacial (a; that is, at $401 \mathrm{kyr}$ ago; see also Supplementary Fig. 1) or at the beginning of that hiatus (b; that is, at 410 kyr ago). sites considered by Bowen ${ }^{5}$. Therefore, correcting an inferred sea-level peak of 6-9 $\mathrm{m}$ for this GIA-induced contamination yields a predicted ESL $\sim 1 \mathrm{~m}$ higher (that is, $7-10 \mathrm{~m}$ ), in accord with the residual highstand elevations at Bermuda and the Bahamas cited above (Supplementary Table 1).

In the Supplementary Information we present results of sensitivity tests related to GIA predictions. First, we extend the duration of the MIS 11 hiatus in ice mass change from 9 to $14 \mathrm{kyr}$. In this case, the GIAinduced elevation of MIS 11 shorelines at sites within the Laurentian peripheral bulge are predicted to increase by $\sim 1-2 \mathrm{~m}$ when viscosity model LM is adopted, yielding residual MIS 11 highstand elevations of $7.0 \pm 1 \mathrm{~m}$ for Bermuda and 9.9 $\pm 3.6 \mathrm{~m}$ in Eleuthera (Supplementary Table 1), and thus lowering the inferred peak ESL during MIS 11 by $\sim 1-2 \mathrm{~m}$. Second, we considered an alternative viscosity profile, VM2 (ref. 26), characterized by a lower-mantle viscosity that is a factor of two smaller than model LM. In this case, the predicted GIA contribution to MIS 11 highstand elevations within the peripheral bulge is reduced by a factor of $\sim 2$. This reduction yields residual (GIAcorrected) MIS 11 elevations of $15.0 \pm 1 \mathrm{~m}$ and $14.3 \pm 3.6 \mathrm{~m}$ at Bermuda and the Bahamas, respectively, values that appear to be at odds with lower far-field estimates ${ }^{5}$. Last, we performed a Monte Carlo parameter search in which we varied mantle viscosity, lithospheric thickness, and the duration of the modelled hiatus in MIS 11 ice volume changes, and tested for the consistency of the GIA-corrected highstand elevations. This exercise yields a preferred bound on the peak ESL during MIS 11 of 6-13 m.

In summary, observations of MIS 11 highstand features in Bermuda and the Bahamas must be corrected for the significant contaminating signal of GIA before these data are used to infer peak ESL during the MIS 11 interglacial. We conclude that ESL reached $\sim 6-13 \mathrm{~m}$ above the present-day value in the late stages of MIS 11. It is unlikely that ocean thermal expansion contributed more than $\sim 1 \mathrm{~m}$ to this inference ${ }^{13,27}$. Therefore, although this estimate of peak ESL indicates significant collapse of both the WAIS and GIS during the MIS 11 interglacial, it rules out any significant melting of the EAIS during this unusually prolonged period of ice age warmth.

Received 30 September 2011; accepted 23 January 2012.

Published online 14 March 2012.

1. Hearty, P. J., Kindler, P., Cheng, H. \& Edwards, R. L. A + 20 m middle Pleistocene sea level highstand (Bermuda and the Bahamas) due to partial collapse of Antarctic ice. Geology 27, 375-378 (1999).

2. Olson, S. L. \& Hearty, P. J. A sustained $+21 \mathrm{~m}$ sea level highstand during MIS 11 (400 ka): direct fossil and sedimentary evidence from Bermuda. Quat. Sci. Rev. 28, 271-285 (2009).

3. van Hengstum, P., Scott, D. B. \& Javaux, E. Foraminifera in elevated Bermudian caves provide further evidence for $+21 \mathrm{~m}$ eustatic sea level during Marine Isotope Stage 11. Quat. Sci. Rev. 28, 1850-1860 (2009).

4. McMurtry, G. M. et al. Elevated marine deposits in Bermuda record a late Quaternary megatsunami. Sedim. Geol. 200, 155-165 (2007).

5. Bowen, D. Q. Sea level $\sim 400000$ years ago (MIS 11): analogue for present and future sea-level? Clim. Past 6, 19-29 (2010).

6. Velicogna, I. \& Wahr, J. Measurements of time-variable gravity show mass loss in Antarctica. Science 311, 1754-1756 (2006).

7. Luthcke, S. B. et al. Recent Greenland ice mass loss by drainage system from satellite gravity observations. Science 314, 1286-1289 (2006).

8. Shepherd, A. \& Wingham, D. Recent sea-level contributions of the Antarctic and Greenland ice sheets. Science 315, 1529-1532 (2007).

9. Rignot, E. et al. Recent Antarctic ice mass loss from radar interferometry and regional climate modelling. Nature Geosci. 1, 106-110 (2008).

10. Thomas, R. et al. Accelerated sea level rise from West Antarctica. Science $\mathbf{3 0 6}$ 255-258 (2004).

11. Chen, J. L., Wilson, C. R., Blankenship, D. \& Tapley, B. D. Accelerated Antarctic ice loss from satellite gravity measurements. Nature Geosci. 2, 859-862 (2009)

12. Velicogna, I. Increasing rates of ice mass loss from the Greenland and Antarctic ice sheets revealed by GRACE. Geophys. Res. Lett. 36, L19503, http://dx.doi.org/ 10.1029/2009GL040222 (2009).

13. Kopp, R. E., Simons, F. J., Mitrovica, J. X., Maloof, A. C. \& Oppenheimer, M. Probabilistic assessment of sea level during the last interglacial stage. Nature 462, 863-867 (2009).

14. Jansen, E. et al. in Climate Change 2007: The Physical Science Basis (eds Solomon, S. et al.) 433-498 (Cambridge Univ. Press, 2007). 
15. Muhs, D. R., Simmons, K. R., Schumann, R. R. \& Halley, R. B. Sea-level history of the past two interglacial periods: new evidence from $U$-series dating of reef corals from south Florida. Quat. Sci. Rev. 30, 570-590 (2011).

16. Otto-Bliesner, B. et al. Simulating Arctic climate warmth and ice field retreat in the last interglaciation. Science 311, 1751-1753 (2006).

17. Bamber, J. L., Riva, R. E. M., Vermeersen, L. L. A., \&. LeBrocq, A. M. Reassessment of the potential sea level rise from a collapse of the West Antarctic Ice Sheet. Science 324, 901-903 (2009)

18. Loutre, M. F. \& Berger, A. Marine isotope stage 11 as an analogue for the present interglacial. Glob. Planet. Change 36, 209-217 (2003).

19. Rohling, E. J. et al. Comparison between Holocene and Marine Isotope Stage-11 sea level histories. Earth Planet. Sci. Lett. 291, 97-105 (2010).

20. McManus, J., Oppo, D., Cullen, J. \& Healey, S. in Earth's Climate and Orbital Eccentricity: The Marine Isotope Stage 11 Question (eds Droxler, A. W., Poore, R. Z. \& Burckle, L. H.) 69-85 (AGU Geophys. Monogr. Ser. 137, 2003).

21. Mitrovica, J. X. \& Milne, G. A. On the origin of postglacial ocean syphoning. Quat. Sci. Rev. 21, 2179-2190 (2002)

22. Kendall, R. A., Mitrovica, J. X. \& Milne, G. A. On post-glacial sea level: II. Numerical formulation and comparative results on spherically symmetric models. Geophys. J. Int. 161, 679-706 (2005).

23. Lambeck, K., Smither, C. \& Johnston, P. Sea level change, glacial rebound and mantle viscosity for northern Europe. Geophys. J. Int. 134, 102-144 (1998).

24. Mitrovica, J.X.\& Forte, A. M. A new inference of mantle viscosity based upon a joint inversion of convection and glacial isostatic adjustment data. Earth Planet. Sci. Lett. 225, 177-189 (2004).
25. Nakada, M. \& Lambeck, K. Late Pleistocene and Holocene sea-level change in the Australian region and mantle rheology. Geophys. J. Int. 96, 497-517 (1989).

26. Peltier, W. R. Global glacial isostasy and the surface of the ice-age Earth: the ICE-5G (VM2) model and GRACE. Annu. Rev. Earth Planet. Sci. 32, 111-149 (2004).

27. McKay, N. P., Overpeck, J. T. \& Otto-Bliesner, B. L. The role of ocean thermal expansion in Last Interglacial sea level rise. Geophys. Res. Lett. 38, L14605, http:// dx.doi.org/10.1029/2011GL048280 (2011).

28. Lisiecki, L. E. \& Raymo, M. E. A. Pliocene-Pleistocene stack of 57 globally distributed benthic $\delta^{18} 0$ records. Paleoceanography 20, PA1003, http://dx.doi.org/10.1029/ 2004PA001071 (2005)

Supplementary Information is linked to the online version of the paper at www.nature.com/nature.

Acknowledgements We thank P. Hearty and D. Bowen for discussions of MIS 11 field data, and J. L. Davis for suggestions regarding data analysis. Support for this research was provided by NSF-OCE-0825293 and OCE-1202632 (M.E.R.), Harvard University (J.X.M.) and the Canadian Institute for Advanced Research (J.X.M.)

Author Contributions This study was planned, undertaken and written jointly.

Author Information Reprints and permissions information is available at www.nature.com/reprints. The authors declare no competing financial interests. Readers are welcome to comment on the online version of this article at www.nature.com/nature. Correspondence and requests for materials should be addressed to M.E.R. (raymo@ldeo.columbia.edu). 